\title{
Kara mayınlarının tespiti için askeri eğitim simülasyonu tasarımı: Bir araştırma ve ön çalışma
}

\author{
Merve VAROL ARISOY ${ }^{1, *}$, Ecir Ŭ̆ur KÜÇÜKSİLLE ${ }^{2}$, Ayhan ARISOY ${ }^{3}$ \\ ${ }^{I}$ Mehmet Akif Ersoy Üniversitesi, Enformatik Bölümü, İstiklal kampüsü, Burdur. \\ ${ }^{2}$ Süleyman Demirel Üniversitesi, Mühendislik Fakültesi, Bilgisayar Mühendisliği Bölümü, Batı kampüsü, \\ Isparta. \\ ${ }^{3}$ Süleyman Demirel Üniversitesi Bilgi İşlem Daire Başkanlı̆̆ı, Batı kampüsü, Isparta.
}

Geliș Tarihi (Recived Date): 23.01.2017

Kabul Tarihi (Accepted Date): 16.05.2017

\begin{abstract}
Özet
Mayınların çeşitli donanımsal yapılara sahip olması ve farklı tiplerdeki üretiminin sürekli artması nedeniyle hem mayının saha içerisinde tespiti hem de farklı özellikteki bu mayınların temin edilerek askeri eğitimin verilmesi zorlaşmıştır. Bunun neticesinde, verilen mayın tarama ĕ̈itimleri teori düzeyinde kalmıştır.

Bu çalışmada mayın tarama eğitimini daha çok uygulamaya dönük bir hale getirebilmek için bir simülasyon geliştirilecektir. Simülasyonda kullanıcının istediği mayın tipini, araziyi ve toprak koşulunu seçebileceği bir ortam yaratılacaktır. Ayn zamanda simülasyondaki sanal asker ile dışarıdaki gerçek askerin eş zamanlı olarak koordineli bir biçimde çalışması sağlanacaktır. Bunun için, gerçek askerin kullanacă̆ aygıt ile sanal askerin yönlendirmesi yapılacaktır. Bu çalışma ile askerlerin birçok mayın tipini tanıyabildiği yeterli bir pratik ĕgitim almalarl amaçlanmaktadır. Bahsedilen simülasyon uygulamasını geliştirebilmek için, dünyada kullanılan mayın tarama cihaz ve yöntemleri hakkında bilgi verilmiştir. Ayrıca, gerçekleştirilecek mayın tarama ĕ̆itim simülatörü yazılımının kapsamı anlatılarak, hedeflenen çıktılar ortaya konmuştur.
\end{abstract}

Anahtar Kelimeler: Askeri amaçlı mayın arındırma, insani mayın temizleme, mayın tarama eğitimi, mayın temizleme yöntemleri, simülatör, sanal gerçeklik.

\footnotetext{
*Merve VAROL ARISOY, mvarisoy@mehmetakif.edu.tr, http://orcid.org/0000-0003-2085-1964 Ecir Uğur KÜÇÜKSİLLE, ecirkucuksille@sdu.edu.tr, http://orcid.org/0000-0002-3293-9878 Ayhan ARISOY, ayhanarisoy@sdu.edu.tr, http://orcid.org/0000-0003-3353-7667
} 


\title{
Military training simulation design for detection of landmines: A research and pre-study
}

\begin{abstract}
Because of the having various hardware structures of mines and increased production of different types, both retaining them in their field and by providing various types of these mines it has become difficult to give military training as a result of this, given mine detecting trainings remained at much theory level.

In this study in order to make this training more practically oriented a simulation will be developed. In simulation an environment will be created in which the user can select the type of mine, land and soil conditions that he wanted. At the same time, the simulated virtual soldier and the real soldier outside will work simultaneously in a coordinated manner. For this, the virtual soldier will be guided by the device that will be used by the real soldier. With this study it is aimed to obtain an adequate practical training that soldiers could recognize the many mine type. In order to improve the mentioned simulation application, information about mine detection devices and methods used in the world is given. In addition by describing the scope of the training simulator software, the targeted outputs have been revealed.
\end{abstract}

Keywords: Demining methods, humanitarian demining, military mine removal, minesweeper education, simulator, virtual reality.

\section{Giriş}

Mayın üretiminin gittikçe kolaylaşması ve etki gücü yüksek bir savunma silahı olması, mayın kullanımını yaygın bir hale getirmiştir. Mayınları coğrafi bir bölgeye yerleştirmek, onları tespit edip sonra da imha etmeye göre daha az uğraş gerektirir. Çünkü günümüzde mayınların plastik, ağaç gibi malzemelerden imal edilmesi ayrıca ateşleyicisindeki iğnesi dışında başka bir metal bir parça ihtiva etmemesi, onların tespitini zorlaştırmaktadır [1]. Mayın tarama ve tespit etme askeri ve insani açıdan ele alınmıştır. Askeri amaçlı olana mayın temizleme, insani amaçla yapılana ise mayın arındırma denilmektedir. Askeri ve insani amaçla yapılan mayın temizleme işi birbirlerinden farklı şekillerde ilerlemektedir. Askeri amaçlı olanda hız önemli bir faktördür. Çünkü mayınlı arazide askerin hızlı bir biçimde ilerlemesi gerekir ayrıca bu temizleme işi, ateş altında iken yapılıyor olabilir [2].Bununla birlikte askeri amaçlı yapılan mayın temizlemede arazinin tümü mayından arındırılmaz sadece gidiş güzergâhı üstünde bulunan mayınlar temizlenir. Fakat insani amaçlı yapılan mayın arındırmada söz konusu tüm sahanın temizlenmesi ve orada yerleşimin tekrar güvence altına alınması gerekir [3].

\subsection{Askeri amaçlı mayın temizleme}

Askeri amaçlı mayın temizlemede bugüne kadar mekanik mayın temizleme, yoğun top ateşine tutma, araziyi yakma, Bangalor torpidosu, roketle firlatılan infilaklı fitille mayın tarlasından geçit açma sistemi gibi yöntemler kullanılmıştır [2]. 
Mekanik mayın temizleme yöntemi, yeke sistemlerini, mayın silindirlerini, mekanik kazıyı, mayın temizleme pulluğu kullanımını içerir. Son zamanlarda kullanılan gelişmiş mekanik temizleme yöntemleri uzaktan kumandalı sistemleri de kapsar. Her ne kadar mekanik temizleme sistemleri başta askeri amaçlı geliştirilmiş olsa da insani amaçla yapılan mayın temizleme işinde de kullanılmaktadır [3]. Yoğun top ateşine tutma yönteminde, arazinin seçili tüm bölümleri hava bombardımanına tutularak bir ilerleme kaydedilmektedir. Bu yöntemde büyük çaplı arazilerde temizleme gerçekleştirilir [4]. Bangalor torpidosu yöntemi, birbirine bağlı birkaç adet boru içine patlayıcının yerleştirilmesi prensibine dayanır [5]. Roketle firlatılan infilaklı fitille mayın tarlasından geçit açma sistemi de Bangalor torpidosu yöntemine benzer. Burada da mayın tarlası üzerinde gedik açıp bu gediklere boruların yerleştirilmesi ve boruların içine de patlayıcı malzemelerin konması söz konusudur [6].

\subsection{Insani amaçlı yapılan mayın temizleme}

İnsani amaçlı yapılan mayın temizlemede ise başlıca olarak, mayın dedektörü ya da mayın çubuğu kullanılarak manuel algılama, mayın tarama köpeklerinden ve farelerden yararlanma, zırhlı araçları kullanarak mekanik temizleme, teleopere ve otonom araçların kullanımı gibi yöntemlerden faydalanılmaktadır [2].

İnsani amaçlı yapılan mayın temizleme yöntemlerinden olan mayın dedektörü ya da mayın çubuğu kullanılarak manuel algılama, \%99,6'lık bir mayın temizleme başarısı oranına sahiptir. $\mathrm{Bu}$ yöntemin temel işlevi mayını algılama ve konumunu tespit etmektir. Edinilen bu veriler de imhanın daha sonraki aşamalarında kullanılmaktadır. $\mathrm{Bu}$ yöntem mayın tespitinde ve imhasında etkilidir fakat yavaş bir sistemdir. Yöntemi yavaşlatan etken de, toprak üzerindeki herhangi bir madeni cisimde bile dedektörün alarm vermesidir. Ayrıca bu konuda eğitilmiş yoğun insan gücünü gerektirmektedir [7].

İnsani amaçlı yapılan mayın temizleme probleminin çözümünde hayvanlardan da yararlanılır. Hayvanların bir insana oranla çok daha az bir ağırlığa sahip olmaları nedeniyle üzerinde bulundukları bir mayını patlatmalarının düşük bir olasılık olması, yöntemi tercih edilebilir kılmıştır [8]. Hayvanların kullanıldığı tarama faaliyetlerinin detayları ve başarı oranları 2.1.2'deki başlıkta verilmektedir.

Zırhlı araçları kullanarak yapılan mekanik temizleme, dümen sisteminin, mayın silindirlerinin, mekanik kazının, mayın pulluğunun ve mayın yarıklarının kullanımını içerir. Dedektör ihtiva etmezler. Mekanik temizleme sistemlerinin avantajı kısa sürede büyük çapta araziyi temizleyebilmesidir. Fakat bu sistem de $\% 100$ bir temizleme başarısına sahip değildir ve manuel algılama yöntemleriyle desteklenmelidir [7]. ELADIN [9] isimli proje mekanik temizleme sistemlerine bir örnektir. Ayrıca yüksek basınçlı su kullanılarak mayınları tespit etme ve onları etkisizleştirme üzerine çalışmalar da yapılmıştır [10].

Mayın tarama probleminde teleopere araçlar da kullanılmaktadır. Bu araçlarda bir robot insanın yerini alır ve operatör uzaktan, video kameraları kullanarak aracı kontrol edebilir. Tehlikeli cismin konumunun az çok bilindiği operasyonlarda kullanılmaktadır [11]. Şekil 1'de teleopere bir araç gösterilmektedir. 


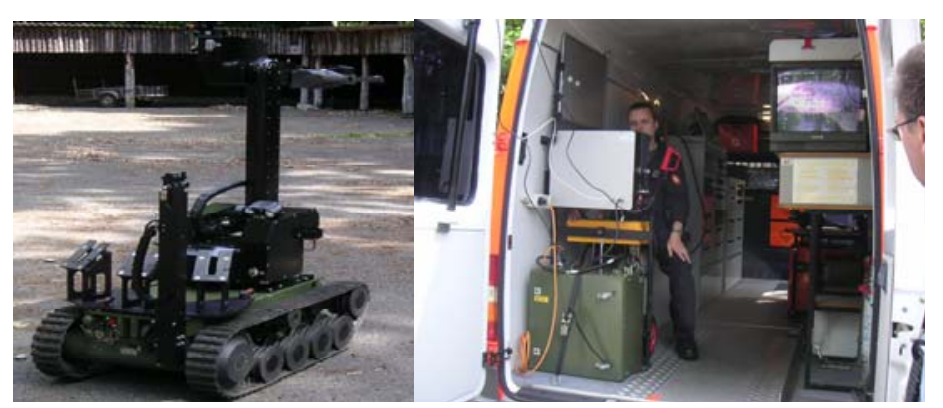

Şekil 1. Uzaktan kontrol edilen bir robot ve kumanda paneli [11].

Yarı otonom mayın tarama robotunun bir versiyonu da Ishikawa et al. 'un çalışmalarında verilmiştir [12].Yarı otonom robotların kullanıldığı Şekil 2'deki çalışmada, robotik araçların üzerine monte edilen GPR sisteminden faydalanılmıştır. GPR sistemini elektromanyetik indüksiyon (EMI) sensörleri ve metal dedektörleri birleştirerek geliştirmişlerdir. $\mathrm{Bu}$ robotu kullanan operatörler yeraltı görüntü resimlerine bakarak resimdeki bir gölgenin gerçek bir mayın olup olmadığını değerlendirmektedirler [11].

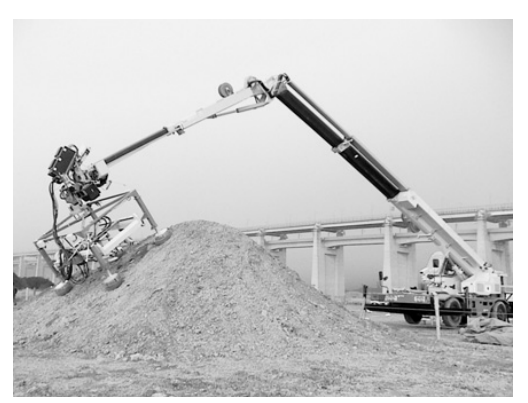

Şekil 2. Geliştirilmiş bir mayın tarayıcı [12].

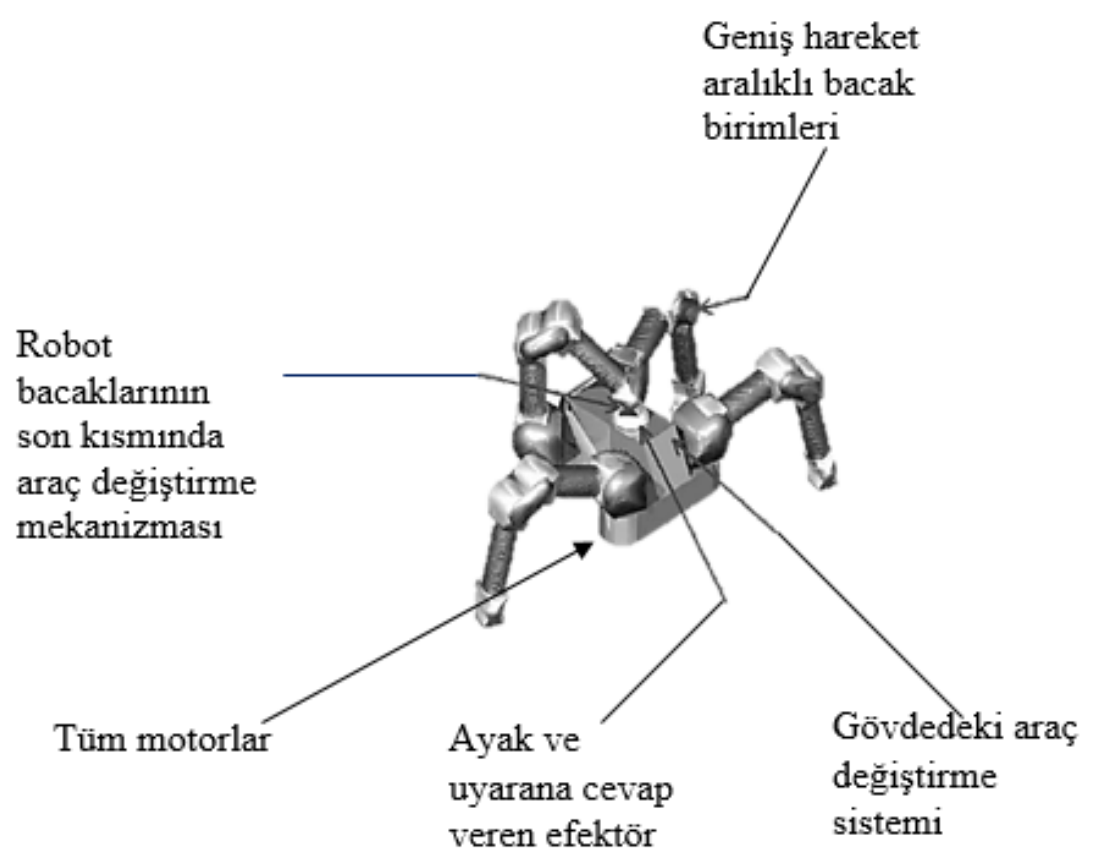

Şekil 3. TITAN-IX robotu[13]. 
Otonom bir robotun kullanıldığı Şekil 3'deki çalışmada geleneksel yürüyüş yapan robotun aksine 4 bacaklı yürüyebilen ve bir idareci tarafından yönlendiriliyormuş gibi bacaklarını kullanabilen TITAN-IX mayın tarama robotu tasarlanmıştır. Daha geniş alanlarda arama yapmayı sağlayan bu robotun farklı mayın temizleme görevlerinde kullanılmak üzere çeşitli araçları bulunmaktadır [11].

İnsani amaçla mayın temizlemede kullanılan bir diğer robot Gonzalez et al 'un çalışmalarında verilmişstir [15].BSA (Backtracking Spiral Algorithm) adını verdikleri yeni bir çevrimiçi kapsama algoritmasından bahsetmişlerdir. Ayrıca Gonzalez ve Gerlein çalışmalarında BSA algoritmasının geliştirilmiş halini sunmuşlardır [20]. Çok etmenli bir yaklaşımı temel alan ve robotun izleyeceği yolun kapsanmasını sağlayan çoklu robot platformu önermişlerdir. BSA-CM isimli bir robotun izleyeceği yolun kapsamının belirlenmesi üzerine bir algoritma geliştirmişlerdir.

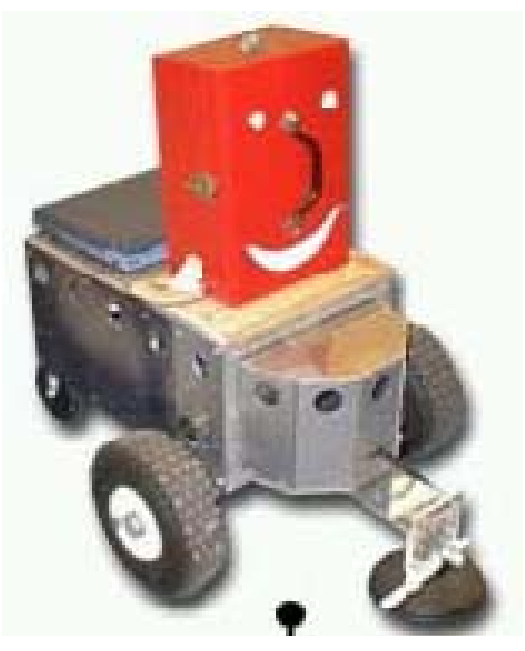

Şekil 4.Finder robotunun son montajlanmış hali [14].

Şekil 4'deki çalışmada bir mayın temizleme robotunun izlediği yolun planlanması üzerine sensör tabanlı bir algoritmadan bahsetmişlerdir. Ayrıca daha hızlı yol planlaması adına yapılmış askeri nitelikli çalışmalar da mevcuttur [16, 17]. Kara mayınının tespiti için kartezyen platformu da önerilmiştir. Bu çalışmada robot mayın araması yaparken mayın temizleme sensörlerinin pozisyonunu düzenleyebilmektedir $[18,19]$.İnsani amaçla yapılan mayın tarama probleminin çözümünde hava kökenli yöntemler de bulunmaktadır [21, 22].

Şekil5'de insani amaçla yapılan mayın temizleme yöntemleri verilmiştir. $\mathrm{Bu}$ yöntemlerden gri renkle belirtilen en çok kullanılan yöntemlerdir. 


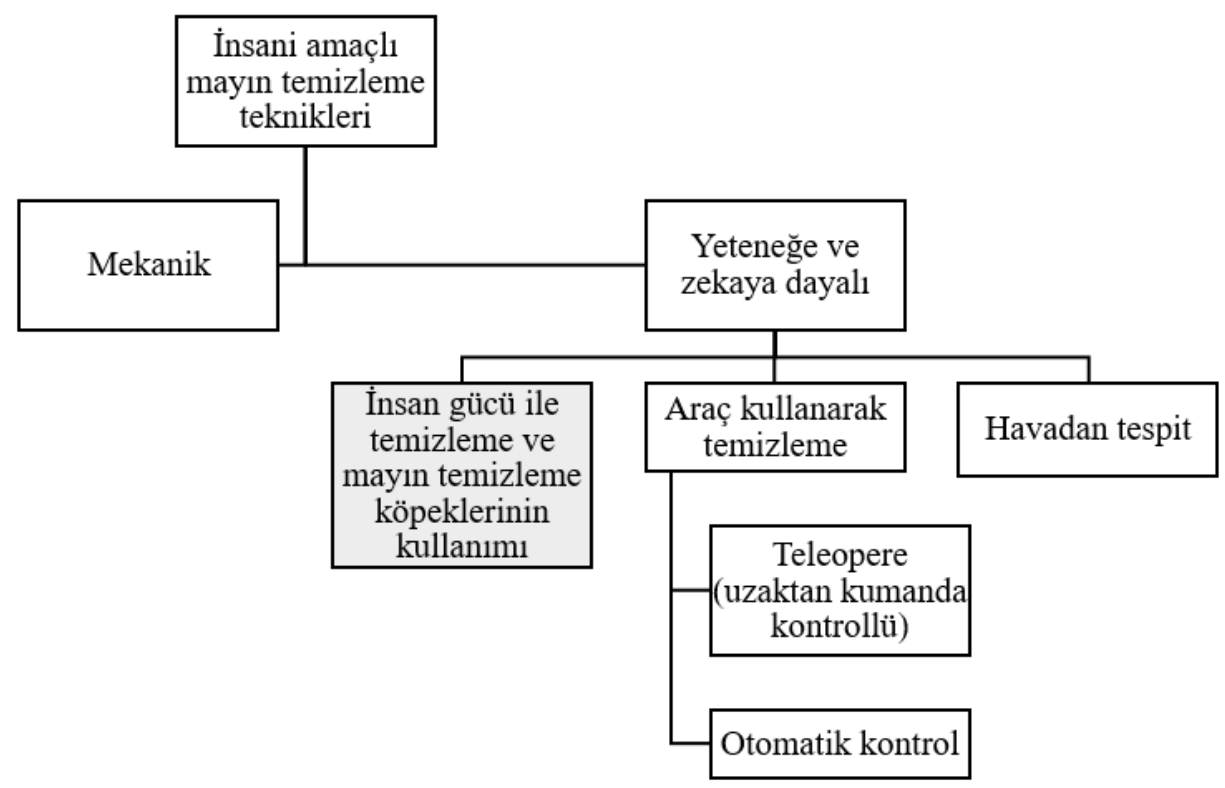

Şekil 5. İnsani amaçlı mayın temizlemede kullanılan yaklaşımlar [11].

\section{Patlayıcı algılama metotları}

\subsection{Patlayıc izi algılama}

\subsubsection{Kimyasal metotlar}

Kütle spektrometresi metodunda, hava numunesi iyonize edilmek amaciyla bir vakum odasına sokulur. İyon hareketliliği spektrometresi metodunda, patlayıcı moleküllerinin bir reaktör içerisinde iyonize edilmesiyle oluşturulur. Daha sonra bu iyonlar hızlandırılır ve kütle/yük oranlarına göre ayrıştırılır. Patlayıcı olmayan maddeler tarafindan uyarılıp yanlış alarm verebildiği için hassasiyet derecesi düşük olan bir yöntemdir [23]. Kızılötesi emilim spektroskopisi metodu, moleküler titreşimlerin kızı̈ötesi spektrumunda karakteristik frekanslarının olduğu gerçeğini benimser [23, 24]. Opto akustik spektroskopi metodu, moleküller tarafindan emilen optik enerjinin gevşeme işlemleri vasıtasıyla kısmen 1sı enerjisine dönüştüğü gerçeğini benimser [24, 25]. Raman saçılması yönteminde, ışı̆̆ın moleküller veya atomlar tarafından esnek olmayan partiküllerinin saçılması söz konusudur. $\mathrm{Bu}$ yöntemin mayın tarama uygulamaları için hassasiyet derecesi düşüktür [24, 26]. Elektronik koku algilayıcılar yönteminde birçok sensörün örüntü tanıma algoritmalarıyla birleştirilmesiyle yapay bir koku alma sistemi oluşturulur [24]. İmmuno-kimyasal sensörler yöntemi,immunoanalizlerin hedef analit ile belirli bir antikor arasındaki reaksiyonunu algılaması üzerine kuruludur [27]. Bu yöntemde türler antijen-antikor reaksiyonuna göre yüksek seçicilikle tanımlanır. Taşınabilir fiberoptik bio sensörler patlayıcı maddeleri tanımlamak için fiber optik problara immünoanaliz uygularlar [28]. Analiz edilmiş bio sensörler TNT ve RDX gibi paylayıcıları belirli bir miktarda tespit edebilmektedirler [29]. Miktar tespiti renk değişimini gözlemleyerek ya da radyoaktivite veya flüoresanı ölçerek yapılmaktadır [55]. Elektronik koku alma yöntemlerinde çapraz reaktif sensör dizileri örüntü tanıma algoritmalarıyla birlikte kullanılarak güçlü bir koku ayrım sistemi oluşturulmaya çalışılmaktadır [30]. Bu yöntemde floresan polimer, optik fiber, polimer filmler, altın nano tanecikler, basınçsal elektrikli materyaller, mikro elektromekanik sistemler gibi sensörlerden yararlanılmıştır [31]. 


\subsubsection{Biyolojik metotlar}

Biyolojik metotlarda, bal arıları [32], dev Afrika sıçanları [33], mayından sızan nitrous oxide'e tepki olarak rengi kırmızıya dönen hardal bitkisi [34], TNT'nin bulunduğu ortamlarda ultraviyole 1şık altında genetik olarak üretilmiş bioreporter bakterisi [35], gibi hayvanların ve bitkilerin kullanımı söz konusudur [2].

Arılar, gıda ile patlayıcı kokusunu ilişkilendirmek için eğitilmişlerdir. Patlayıcı algılamada, arıların takip edilmesinin zorluğundan dolayı kullanımlarının sınırlı olduğu [36]'deki çalışmada belirtilmiştir.

Koku algılayarak mayın tespit etmede köpeklerden yararlanılmıştır. Mayının içindeki patlayıcının kokusunun bu iş için eğitilmiş köpeklerce algılanmasıyla mayının yeri tespit edilmektedir. Yöntemin etkinliği köpeklerin yorulma ve dikkat faktörlerine bağlıdır. Bu yüzden sistemin güvenilirliği düşüktür [7].

Deyholos ve ark. Arabidopsis Thaliana isimli bir bitkinin patlayıcıdan çıkan azot dioksit ile etkileşime geçtiğinde rengini değiştirdiği belirlenmiştir [37]. Fakat bu bitkiyi kullanarak algılama bazı problemleri de açığa çıkarmaktadır. Çünkü bazı bakteriler de azot dioksiti açığa çıkarmaktadır. Bu da yanlış algılamalar doğurabilmektedir [38].

\subsection{Toplu patlayıcı algilama}

\subsubsection{Nötron analiz yöntemleri}

$\mathrm{Bu}$ yöntemin termal, hızlı, darbeli hızlı, darbeli hızlı termal nötron analizi şeklinde alt başlıları bulunmaktadır. Termal nötron analizi yönteminde, nötronlar bir çekirdek tarafından emildiğinde gama ışınları o çekirdeğe özgü bir enerji ile yayılır. Seçiciliği düşük, yanlış alarm oranı fazla hantal bir teknolojidir [39]. Hızlı nötron analizi yöntemi gama radyasyonunu algılamak için geliştirilmiştir. $\mathrm{Bu}$ yöntem patlayıcı içindeki tüm elementleri seçebilme özelliğine sahiptir fakat dezavantajlı yani pahalı ve kompleks bir yapıda olmasıdır [40]. Darbeli hızlı nötron analizi yönteminde patlayıcının bileşiminin tanınmasına ayrıca mekânsal bilgisinin ve yoğunluğunun da alınmasına olanak sağlanır.Darbeli hızlı termal nötron analizi yönteminde nötronların uzun ömürlü ışınları uygulanır. Yüksek güvenirlikli ve mobil yapıya sahip bir yöntem olması avantajlarındandır. Fakat mayınlardaki patlayıcının alt kilogram miktarlarını algılamada yetersiz kalmaktadır [41].

\subsubsection{Nükleer dört kutuplu rezonans (NQR)}

$\mathrm{Bu}$ metotta patlayıcı içindeki azot çekirdeklerini uyaran radyo frekansı darbeleri gönderilir. Her bir patlayıcıdan elde edilen spektrum tek olduğu için algılama çok hassastır ve yanlış alarm oranı düşüktür [24]. Yöntemin eksi tarafı düşük sinyal/gürültü oranıdır (SNR) [42]. Ayrica radyo frekansı parazitlerinden ve sicaklıktan etkilenmektedir [43].

\section{Mayın gövdesi algılama}

\subsection{Elektromanyetik metotlar}

\subsubsection{Yer radarı (GPR)}

Geleneksel metal dedektörlerinin çalışma frekans aralığ $10-100 \mathrm{kH}_{\mathrm{z}}$ dir. Bu değer GPR için $1 \mathrm{GH}_{\mathrm{z}}$ dir. $\mathrm{Bu}$ sayede plastik veya tahta kullanılarak imal edilmiş mayınlar bile algılanabilmektedir. Yöntemin eksi yanı ise toprak yüzeyinde meydana gelen nem 
değişimlerinden ve toprak üzerindeki yabancı nesnelerden (ağaç, taş gibi) etkilenmesidir [2].

\subsection{2. Çift sensör teknolojisi}

Çift sensör yönteminde GPR ve metal dedektör teknolojisi tek bir cihazda birleştirilmiştir [2].

\subsubsection{Metal dedektörleri}

Mayın tarama probleminin çözümünde kullanılan bir diğer yöntem metal dedektörleridir. $\mathrm{Bu}$ dedektörlerin çalışma prensibi, dedektörün arama başındaki bobinlerle manyetik alan oluşturulup bu alanın metal cisimlere çarpmasıyla oluşan kaçak akımların sinyal haline dönüştürülerek operatörün kulaklığına ses olarak ulaşması biçimindendir. Yalnız, askeri harekât yapılmış ya da bombalanmış alanlarda toprakta mayın dışında birçok madeni parçanın bulunması ve bunların da yalnızca ses sinyali ile algılanması mayın tespitinde hataya sebep olmaktadır. Çünkü böyle bir arazide arama yapan personele çok sayıda ikaz sinyali gelmektedir ve gerçekte mayın kaynaklı olan ikaz sinyaller bile mayın dışı bir madeni parçadan kaynaklı olarak düşünülmektedir. Bunun sonucu olarak da o alanda olmadığı kabul edilen mayınların ileriki bir zamanda patlaması kaçınılmazdır [1].

Özellikle tahrip edici anti-personel mayınlarının son zamanlarda tek madeni parçası olan ateşleme iğnesi de sert plastikten yapılmaya başlanmıştır. Mayını tespit için mayın içindeki bu yegane madeni parça da kaldırıldığından mevcut mayın dedektörleri ile bu mayınların tespiti artık tamamıyla imkansız hale gelmiş ve eldeki kısmen güvenilir metal dedektör sistemi de kullanılamaz hale gelmiştir [1].

\subsubsection{X-Işını geri yansıması}

$\mathrm{Bu}$ yöntem, gömülü basınç levhalarını saptamak için kullanılmaktadır [44].X-ray üretecinin boyutu ve ağırlığı nedeniyle taşınabilir bir yöntem değildir. Ayrıca toprağa yeterli miktarda nüfuz edebilmek için güç gereksinimi vardır [45].

\subsubsection{Elektriksel empedans tomografisi yöntemi (EIT)}

$\mathrm{Bu}$ yöntemde yeraltının iletkenlik haritasını oluşturmak amacıyla toprağa yerleştirilen 2 boyutlu elektrot dizilerinden faydalanılır. Elde edilen iletkenlik görüntüleri kara mayını gibi anormallikleri tanımlamak için kullanılır. Bu teknoloji özellikle islak toprak üzerinde çalışmaya uygundur. Çünkü zeminin sslak olması iletkenliği arttırmaktadır. EIT sensör başlıkları oldukça az bir maliyete tek kullanımlık olarak yapılmaktadır ve uzaktan toprağa yerleştirilebilmektedir. Bu teknoloji kuru toprak için elverişli değildir ve elektriksel gürültüden etkilenmektedir [46]. Ayrıca bu yöntemin çözünürlüğü GPR yönteminin çözünürlüğüne ulaşmamaktadır [42].

\subsection{Mekanik metotlar}

\subsubsection{Sismik-akustik teknikler}

Sesinya da sismik dalgaların bir kara mayınına çarpması sonucu mayından yansıyan dalgaların toprak yüzeyinde titreşimler oluşturmasına dayanmaktadır [24]. Chi et al. 'un çalışmalarında da bu tekniğin yanlış alarm oranının düşük olduğu belirtilmiştir [47].

\subsubsection{Ses üstü dalga yöntemi}

$\mathrm{Bu}$ yöntemde, yayılan ses üstü dalgalar farklı akustik özelliklere sahip materyaller arasında yansıtılmaktadır. Yöntemin, sslak zeminlerde toprağa iyi nüfuz ettiği 
belirtilirken aynı zamanda hava ile yer arasındaki yüzeyde sorunlarla karşılaştığı da bildirilmiştir [38].

\subsubsection{Prodding (çivili sopa) yöntemi}

$25 \mathrm{~cm}$ uzunluğuna bir sopa ile yer yüzeyinde küçük bir açı oluşturarak toprakta mayın olup olmadığını garantilemek adına uygulanan bir yöntemdir [64]. Oldukça yavaştır ayrıca araştırma esnasında mayınlar sopa tarafından infilak ettirilebileceğinden dolayı tehlikeli bir yöntemdir [45].

\section{Kızlötesi ve hiperspektral algılama}

Kızılötesi ve hiperspektral algılama, kara mayınından yansıtılan veya mayın tarafindan emilen elektromanyetik radyasyonun düzensiz varyasyonlarının tespitine dayanmaktadır [24].

\subsection{Milimetre dalga radarı (MMWR)}

$\mathrm{Bu}$ teknik, milimetrik dalga bandında toprağın yüksek yayılım ve düşük yansıtım yaptığı gerçeğine dayanmaktadır. Metaller ise bunun tam tersi bir yapıya sahiptir [43]. MMWR tekniğinin metal cisimlerin tespiti için iyi bir teknik olduğu fakat plastik içerikli cisimleri bulmada o kadar verimli olmadığ 1 Cardona et al. 'un çalışmalarında belirtilmiştir [24].

\subsection{Kızılötesi kameralar (IR)}

Termal bir algılama yöntemi olan IR kameralar, mayına yakın alanlardaki günlük sıcaklık değişimleriyle mayını çevreleyen alanlardaki sıcaklık değişiminin birbirinden farklı olduğu gerçeğine dayandırılmaktadır [44]. IR kameraların verimliliği, hava koşulları, kara mayının boyutu ve içeriği gibi farklı faktörler tarafından etkilenmektedir. Derinlerde gömülü cisimleri tespit etmede çok etkili değildir ve bireysel mayınlardan ziyade mayınlı alanların tespiti için daha uygun bir yöntemdir [38].

\subsection{Lazer kaynakl arıza spektroskopisi (LIBS)}

LIBS yöntemi, materyali atomlarına ve iyonlarına ayrıştırarak yüksek sıcaklıkta mikro plazma üretmek için yüksek yoğunluklu lazer kullanmaktadır. Elektron iyon çarpışmaları sürekli bir spektrum üretmektedir. $\mathrm{Bu}$ spektrumun analizi de element tanımlamayı mümkün kılmaktadır. $\mathrm{Bu}$ yöntem anti-personel ve anti-tank mayın gövdelerinin tespitinde kullanılmaktadır [45]. LIBS yönteminin bir probun geliştirilmesine de öncülük ettiği Church et al. 'un çalışmalarında belirtilmiştir [46].

\subsection{Görünür ışık}

Bu yöntem görüntüleme için optik bir sistem kullanarak görünür dalga aralığında ışığın tutulması prensibine dayanır [47]. Yöntemin dezavantajı, bitki örtüsünün olduğu alanlarda yeşillikler tarafından engellenmesidir. Bu yüzden bitki örtüsünün seyrek olduğu düz alanlarda tercih edilir [38]. Yüzeye yayılmış mayınlara için daha elverişli bir yöntemdir [24].

\subsection{Optik ışık algılama ve uzaklık ölçümü (LIDAR)}

$\mathrm{Bu}$ yöntemde doğrusal polarize bir 1şıkla nesne aydınlatıldıktan sonra geri saçılan 1şıktaki polarizasyon değişiklikleri ölçülmektedir [24]. Hedef nesnelerden saçılan polarizasyon değerine göre bir hesaplama yapılarak nesne ayrımına gidilmektedir. Chi 
et al.'un çalışmalarında da lazer polarimetrik görüntülemenin geleneksel yoğunluk görüntüleme yöntemine kıyasla kamufle edilmiş cisimleri tespit etmede daha başarılı sonuçlar verdiğinden bahsedilmiştir [47].Yöntemin eksik tarafi ise yeraltı görüntüleme yeteneğine sahip olmaması ve bitki örtüsünün olduğu arazilerde istenilen kararlılıkta çalışmamasıdır [24].

\section{Mayın taramada sensör kullanımı}

Sensörler, otomatik mayın temizleme sistemleridir [11]. Sensörlerin mayın temizleme probleminin çözümü alanında kullanımı yaygındır ve bunları kullanılarak yapılmış çalışmalar bulunmaktadır [48]. Otomatik bir mayın temizleme sisteminde görüntüleme sensörleri ve örüntü tanıma teknikleri kullanılmaktadır [49]. Fakat toprağa yerleştirildikten sonra üzerinden uzun zaman geçmiş mayınları yalnızca görüntüleme sensörlerini kullanarak tespit etmek zordur. Çünkü zaman içerisinde toprağın yapısında değişmeler olması ve toprağın bitki örtüsüyle kaplanması kaçınılmazdır. Bu yüzden geliştirilen sensörler de yer altını ve tahribat almamış cisimleri algılama özelliğine sahip olmalıdır. Öte yandan her bir mayın tipinin kendine has karakteristiği vardır ve farklı içerikli bileşenlerden oluşmaktadır. Bu bileşenlerin tümünü tespit edebilen bir sensör sistemi bulunmamaktadır. Onun yerine bir mayını oluşturan bileşenleri birbirinden bağımsız algılamak daha olasıdır [11].

Bir diğer sensör tabanlı teknoloji ise termal radyasyonun ölçülmesine dayanmaktadır. $\mathrm{Bu}$ amaç için pasif mikrodalga radyometreleri ve kızılötesi kameralar (IR) kullanılmaktadır. IR kameraları, pasif mikrodalga radyometrelerine göre daha yaygın bir kullanıma sahiptir. Çünkü bu kameralar büyük bir tarama alanında daha çabuk sonuç vermektedirler [11].

Ölçülen radyasyon değerinden bir objenin sıcaklığı çıkarılabilmektedir ve toprağın sıcaklığından farklı bir sıcaklık değeri varsa o objenin mayın olabileceği ile ilgili kısmen bilgi vermektedir. Fakat yalnızca sicaklık parametresi o cismin mayın olup olmadığını algılamak için yeterli değildir. Bu yüzden termal görüntülerdeki dairesel alanlar bilgisayar aracılığıyla analiz edilmelidir [11]. Messelink et al. ve Cremer et al. çalışmalarında dairelerin analizi için Hough transform ve Tophat filtresi [50, 51], Frigui et al. çalışmalarında ise matematiksel morfoloji kullanılmıştır [52]. Ayrıca bu çalışmalarda kullanılan yaklaşımların biraz değiştirilmiş hali Roughan et al. 'un çalışmalarında verilmiştir [53]. IR sensörler kullanılarak alınan termal görüntülerin analiz edilerek bir cismin mayın olup olmadığına karar verilmesi sırasında ortamda bulunan mayın dışındaki nesneler (çimen vb.) tarama sonuçlarına olumsuz etki edebilmektedir. Bu nesneleri kara mayınlarından ayırt etmek için sanal görüntüleme bilgileri gereklidir [11]. Jarrad veMcMichael'in çalışmalarında topraktaki mayın dış1 nesneleri ayırmakla ilgili ek özelliklerin kullanılması gerektiği belirtilmiştir [54].

Sensörler kullanılarak yapılan çalışmalar değerlendirildiğinde genel yargı tüm mayın tiplerini her türlü hava koşulu altında tanıyabilen bir teknolojini olmadığı yönündendir. $\mathrm{Bu}$ yüzden her bir sensörün kendine ait sınırlamalarının önüne geçebilmek için çoklu sensör kullanılması gerekmektedir $[42,55]$.

Sensör füzyon metodu çoklu sensör teknolojisine bir örnektir. Bu yöntemde GPR ve metal dedektörleri ve bazı durumlarda IR sensörlerinin kullanımı birleştirilmiştir [56]. 
Diğer bir algılama yöntemi de fizikokimyasal yöntemlerdir. Toprağa sızan patlayıcıyı tanımlayabilmek için kütle spektrometresi ve nükleer kuadrupol rezonans gibi spektroskopik analizlere dayandırılmaktadır [57, 58]. Fakat bu teknolojiler pahalı ve yavaştır. O yüzden mayın tarama probleminin çözümünde ek algılama seçeneği olarak görülmektedir [11].

\section{Sistemin aşamaları}

Mayın tarama problemi ile ilgili yapılmış çalışmalar değerlendirildiğinde, bu işin daha çok metal dedektörlerle ya da dümen, parçalayıcı gibi cihazlarla donatılmış zırhlı araçları kullanarak mekanik temizleme şeklinde yapılmakta olduğu görülür [2]. Ayrıca yapılan bazı çalışmaların başarılı olduğu da bildirilmiştir [59]. Ancak bu güne kadar gerçekleştirilen bu çalışmalar mayınları tarama ve imha etmeye odaklanmıştır. Fakat bu tarama sürecinin askerlere eğitilmesi üzerine olan bir çalışma ile karşılaşılmamıştır. Bu noktadan hareketle, soruna mayınları hangi yöntemi ve teknolojiyi kullanarak yok edebiliriz sorgulaması yerine mayınların tespit edilme sürecini, eğitim esnasında askerleri araziye taşımadan aynı zamanda yaşanacak kazaları da bertaraf ederek askerlere güvenli bir eğitim deneyimini gerçekmiş gibi yaşatabilmeyi ne şekilde sağlayabiliriz sorusunun cevabı aranmaya çalışılmıştır. Mayın tarama simülatörü sistemine dair içerik Şekil 6' da belirtilmiştir.

Mayın taraması yapılacak olan coğrafi bölgeye gitmeden, Türkiye'deki gerçek arazi görüntüleri alınarak (gerçek arazi modeli için 3 boyutlu dijital yükseklik verileri kullanılacaktır.), oyun motoruna aktarılmış olan bölgeler arasından seçim yapılarak ilgili arazinin 3 boyutlu modeli simülatöre yüklenebilecek, aynı zamanda farklı tipteki mayınlar (antitank, antipersonel) seçilen zorluk kriterine göre modeli oluşturulan saha üzerinde rastgele bir konumda yerleştirilebilecektir. Arazi seçiminin ardından kullanıcı istediği hava koşullarını (kar, yağmur, güneşli) ve toprak türlerini (kayalık, çakıllı, kumlu, sulu) seçerek simülasyon sahnesinde belirlemiş olduğu bu kriterlere göre arama faaliyetini gerçekleştirebilecektir. Simülasyon sahnesinde iken kullanıcıya 2 farklı dedektör tipinden birini seçme imkanı da sunulacaktır. Yazılımda tanımlanan sanal asker dişarıdan yönlendirilerek saha üzerinde mayın tarama işini gerçekleştirebilecektir. Bir mayına yaklaşmaya başladığında ve ya çok yakınına geldiğinde de mayının tipine göre ses çıkarılacaktır ve askerle mayın arasındaki mesafeye bağlı olarak bu sesin şiddetinde değişmeler olacaktır. Bu sayede eğitim alan askerler onun hangi özelliklere sahip bir mayın olduğunu anlayabileceklerdir. Ayrıca saha üzerine sirf mayınlar değil toprak içinde bulunması çok muhtemel olan konserve kutusu, bozuk para, çivi gibi metal parçalar da yazılımsal olarak dağıtılacaktır. Bu sayede tıpkı gerçek tarama faaliyetlerinde olduğu gibi, bu cisimlere yaklaşırken, askerin dedektörden kulağına gelen sese bir aşinalık kazanması ve bu sayede mayın dışı nesnelere yaklaşırken duyulan ses ile mayına yaklaşırken çıkan ses arasında bir ayrım yapabilme yetisini kazanması sağlanmış olunacaktır. Sıra bir sonraki askerin eğitimine geldiğinde ise çalışılan saha üzerinde mayınlar (tercih edilirse yeni eğitimde başka mayınlar da kullanılabilir) yeni yerlerine rastgele dağıtılabilecektir. İstenirse üzerinde çalışılan saha ile hava ve toprak koşulları bir diğer askeri birlik için değiştirilebilecektir. Sanal askerin mayını tespit etmesi durumunda dışarıdaki gerçek askere bir titreşim verdirilerek onun eğitimle daha iyi bütünleşmesinin yolu açılmış olunacaktır. Eğitim dinamik bir yapıda olacağı için askerlerin her çevre koşulu ve toprak tipinde ayrıca farklı arazilerde gerçek arama faaliyetlerine uygun yetiştirilmesi sağlanacaktır. Bu 
yüzden simülasyon sahnesi dışındaki gerçek sahada yapılan mayın tarama görevlerinde de askerlerin araziye tam bir uyum sağlamaları öngörülmektedir.

Gerçekleştirilecek olan yazılımla, eğitim esnasında yaşanan yaralanmaların ve hatta olası ölümlerin önüne geçilecek hem de güvenli, uygulamalı bir eğitim verilecektir. Yazılımın güvenliliği, son dönemlerin önemli bir teknolojik gelişmesi olan sanal gerçeklik kullanılarak geliştirilecek olmasından kaynaklanmaktadır. $\mathrm{Bu}$ teknoloji sayesinde kullanıcının eğitim alırken gerçek mayınla karşılaşma riski tamamen ortadan kaldırılacağ 1 için son derece güvenli bir sistem oluşturulmuş olunacaktır aynı zamanda gerçekten arazide tarama yapıyormuş hissini de verdiği için normal saha koşullarına uygun bir eğitim verilmiş olunacaktır. Tüm mayınların temin edilip, onların toprağa yerleştirilmesi ve ardından askerler tarafından bulunmasının sağlanması yerine bunların birkaç seçim işleminin ardından çok daha kısa bir süre içinde yapılabilecek olması hem zamandan hem de maliyetten büyük oranda tasarruf ettirecektir. Yazılımın sağlayacağı en önemlisi fayda ise gerçek arazide iken çok büyük hassasiyet gerektiren mayın tespit görevinin ne şekilde yapılması gerektiği herhangi bir kaza riski taşımadan en güvenli haliyle verilmiş olunacaktır.

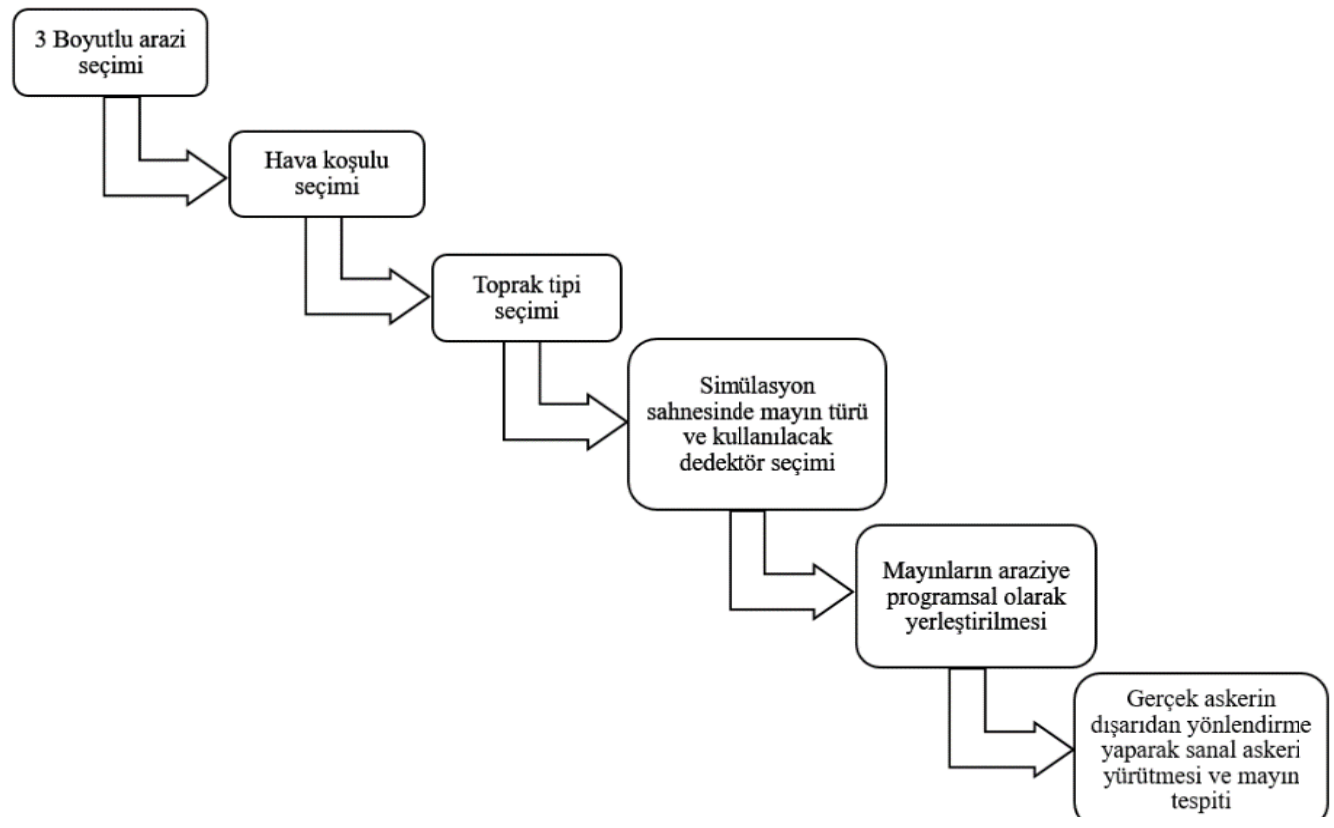

Şekil 6. Sistemin aşamaları.

\section{Sonuç}

$\mathrm{Bu}$ çalışma, kara mayınlarının türleri ve özellikleri hakkında askerlere bir mayın tarama eğitimi vermek ile ilgili bir ön hazırlık çalışmasıdır. Çalışmanın içeriğinde mayın tarama ve imha etmek ile alakalı bu güne kadar kullanılan metotlardan ve asıl amac1 mayın tarama eğitimi vermek üzerine olan bir eğitim yazılımından bahsedilmiştir.

Mayın tarama ve imha ile ilgili yapılan literatür araştırmaları değerlendirildiğinde bu amaç için çoğu kez robotlardan ve çoklu sensör teknolojisinden faydalanıldığı görülmüştür. Robot kullanılarak gerçekleştirilen çalışmaların birçoğu uzaktan kontrollü üzerinde sensörler bulunan robot ile mayın taraması yapma şeklindedir. Fakat bu 
çalışmalar mayını bulup imha etmekle alakalıdır ve fiziksel olarak da tarama yapılan alanda bulunmayı gerektirmektedir. Çoklu sensör teknolojisinde ise farklı mayın özelliklerini tanımlayabilmek için birçok sensör tek bir cihazda toplanmıştır ki Türk Silahlı Kuvvetleri'nde mayın tarama eğitimi veren ilgili kurum ile yapılan görüşmeler sonucunda da şuan böyle bir sistem ile tarama faaliyetlerine devam edildiği öğrenilmiştir. Vermiş oldukları mayın tarama eğitiminde farklı toprak türlerine sahip küçük ölçekli alanlara mayınlar eğitim öncesinde gömülüp askerler tarafindan bunların tespiti istenmektedir. Farklı özelliklere sahip birçok mayını temin edip önce toprağa yerleştirmek ardından bulunmasını sağlamak oldukça zaman ve maliyet gerektiren bir süreçtir. Gerçekleştirilecek olan çalışmada ise hem mayın yerleştirme işlemi kısa bir sürede birkaç seçim işleminin ardından yapılabilecek hem de araziye gidilmeden gerçekten arazi üzerindeymiş hissi yaratılarak mayın tespiti daha güvenli bir hale getirilecektir.

Çalışma sonlandığında mayın tarama işinin çok zahmetli olmasından ötürü bu işlemi gerçeği tam olarak yansıtan sanal ve güvenli bir ortam üzerinde uygulatarak zamandan ve maliyetten tasarruf edilmiş olunacaktır. Çalışmanın en büyük faydası eğitim esnasında yaşanan yaralanmaların önüne geçilebilecek olmasıdır.

\section{Kaynaklar}

[1] Görüntülü mayın bulma sistemi, http://www.canlaser.com/tr/Mines.aspx, (05.01.2017).

[2] Demining, http://en.wikipedia.org/wiki/Demining\#Military_mine_clearance, (05.01.2017).

[3] Clearance of mines and explosive remnants of war, http://www.mineaction.org/issues/clearance, (10.07.2017).

[4] Carpet bombing, http://en.wikipedia.org/wiki/Carpet_bombing,(31.01.2017).

[5] Bangalore torpedo, http://en.wikipedia.org/wiki/Bangalore_torpedo, (25.02.2017).

[6] Mine-clearing line charge, http://en.wikipedia.org/wiki/Mineclearing_line_charge, (16.01.2017).

[7] Introduction to mine clearing technology, http://www.dsta.gov.sg/docs/publications-documents/introduction-to-minelearingtechnology.pdf?sfvrsn=0, (16.08.2016).

[8] Current humanitarian demining methods, http://en.wikipedia.org/wiki/Demining\#Current_humanitarian_demining_metho ds, (19.01.2017).

[9] Eladin, High Pressure Waterjet Laboratory, Rock Mechanics and Explosive Research Center, University of Missouri - Rolla, http://eladin.umr.edu/, (13.02.2007).

[10] Haight, B., Cleaning up an explosive problem: project Eladin uses water to detect, expose and neutralize abandoned land mines, Diesel Progress North American Edition, 12, (2002).

[11] Larionava, S., Automated landmine detection by means of a mobile robot, $\mathrm{PhD}$ Thesis, Faculty of Science and Technology University of Coimbra, Portekiz, (2007).

[12] Ishikawa, J., Kiyota, M. ve Furuta, K., Evaluation of test results of gpr-based antipersonnel landmine detection systems mounted on robotic vehicles, 
Proceedings of the IARP International Work-shop on Robotics and Mechanical Assistance in Humanitarian Demining, 39-44, (2005).

[13] Hirose, S., Yokota, S., Torii, A. ve Ogata, S., Quadruped walking robot centered demining system - development of TITAN-IX and its operation, IEEE International Conferance on Robotics and Automation (ICRA), 1296-1302, (2005).

[14] Acar, E. U., Zhang, Y. P., Choset, H., Schervish, M., Costa, A. G., Melamud, R., Lean, D. C. ve Graveline, A., Path planning for robotic demining and development of a test platform, International Conferance on Field and Service Robotics, 161-168, (2001).

[15] Gonzalez, E., Alarcon, M., Parra, C. ve Zheng, Y. F., BSA: a coverage algorithm, IEEE International Conferance on Intelligent Robots and Systems (IROS),2, 1679-1684,(2003).

[16] Acar, E. U., Choset, H., Zhang, Y. P.ve Schervish, M., Path planning for robotic demining: robust sensor-based coverage of unstructured environments and probabilistic methods, The International Jounal of Robotics Research, 441466, (2003).

[17] Zhang, Y. P., Schervish, M., Acar, E. U. ve Choset, H., Probabilistic methods for robotic landmine search, IEEE International Conferance on Intelligent Robots and Systems (IROS), 1525-1532, (2001).

[18] Rachkov, M. Y., Marques, L.ve de. Almeida, A. T., Multisensor demining robot, Autonomous Robots, 18, 3, 275-291, (2005).

[19] Neves, M. A., Gomes, R. R. ve Costa, R. M., Robô com pernas para desminagemhumanitária, Diploma Thesis, University of Coimbra, Portekiz, (2003).

[20] Gonzalez, E. ve Gerlein, E., BSA-CM: a multi-robot coverage algorithm, Proceeding WI-IAT '09 Proceedings of the 2009 IEEE/WIC/ACM International Joint Conference on Web Intelligence and Intelligent Agent Technology, 2, 383-386, (2009).

[21] Clark, G. A., Sengupta, S. K., Aimonetti, D., Roeske, F.ve Donetti, J. G., Multispectral image feature selection for land mine detection, IEEE Transaction on Geoscience and Remote Sensing, 38, 1, 304-311, (2000).

[22] Kempen, L., Katartzis, A., Pizurica, V., Cornelis, J.ve Sahli, H., Digital signal/image processing for mine detection. part1: airborne approach, In Euro Conference on Sensor Systems and Signal Processing Techniques Applied to the Detection of Mines and Unexploded Ordance, 48-53, (1999).

[23] Caygill, J.S., Davis, F. ve Higson, S.P.J., Current trends in explosive detection techniques, Talanta, 88, 14-29, (2012).

[24] Cardona, L., Jiménez, J. ve Vanegas, N., Landmine detection technologies to face the demining problem in Antioquia, DYNA, 81, 183,115-125, (2014).

[25] Chen, X., Guo, D., Choa, F.S., Wang, C.C. ve Trivedi, S., Standoff photoacoustic detection of explosives using quantum cascade laser and an ultrasensitive microphone, Applied Optics, 52, 26-32, (2013).

[26] Piorek, B.D., Lee, S.J., Moskovits, M. ve Meinhart, C. D., Free-surface microfluidics/surface-enhanced Raman spectroscopy for real-time trace vapor detection of explosives, Analytical Chemistry, 884, 9700-9705, (2012).

[27] Van Emon, J. M. ve Lopez-Avila, V., Immunochemical methods for environmental analysis, Analytical Chemistry, 64, 2, 78A-88A, (1992).

[28] Ma, J. ve Bock, W. J., Fiber-optic sensors for explosives detection, The Open Optics Journal, 7, 141-158, (2013). 
[29] Bakaltcheva, I. B.,Ligler, F. S., Patterson, C. H. ve Shriver-Lake, L. C., Multianalyte explosive detection using a fiber optic biosensor, Analytica Chimica Acta, 399, 13-20, (1999).

[30] Stitzel, S.E., Aernecke, M.J. ve Walt, D.R., Artificial noses, Annual Review of Biomedical Engineering, 13, 1-25, (2011).

[31] Kong, D., Qi, Y., Zhou, L.,Lin, B. ve Li, Z., MEMS based sensors for explosive detection: development and discussion, Proceedings of the 3rd IEEE International Conference on Nano/Micro Engineered and Molecular Systems, 265-269, (2008).

[32] Jerry, J., Bees used in area reduction and mine detection, Journal of Mine Action, 7, 3, (2003).

[33] Reuters, Move over sniffer dogs, here come Africa's rats, http://www.aegis.com/news/re/2004/re040956.html, (02.01.2014).

[34] Amerikan İletişim Vakfi, Mine-sniffing plants, http://acfnewsource.org.s60463.gridserver.com/science/mine_sniffing_plants.ht $\mathrm{ml},(02.01 .2014)$.

[35] Burlage, R. S., Hunt, M., Dibenedetto, J. ve Maston. M., Bioreporter bacteria for the detection of unexploded ordnance excerpt from the demining, Demining Research, http://school.mech.uwa.edu.au/ jamest/demining/others/ornl/rsb.html, (03.01.2014).

[36] Rains, G.C., Tomberlin, J.K. ve Kulasiri, D., Using insect sniffing devices for detection, Trends in Biotechnology, 26, 288-294, (2008).

[37] Deyholos, M., Faust, A.A., Minmin, M., Montoya, R.ve Donahue, D.A., Feasibility of landmine detection using transgenic plants, Proceedings of SPIE, 6217, 62172B-1-62172B-12, (2006).

[38] Kasban, H.,Zahran, O., Elaraby, S.M. ve El-Kordy, M., A comparative study of landmine detection techniques, Sensing and Imaging: An International Journal, 11, 89-112, (2010).

[39] Mcfee, J.E., Faust, A.A., Andrews, H.R., Clifford, E.T.H. ve Mosquera, C.M., Performance of an improved thermal neutron activation detector for buried bulk explosives, Nuclear Instruments and Methods in Physics Research Section A: Accelerators, Spectrometers, Detectors and Associated Equipment, 712, 93-101, (2013).

[40] Sudac, D., Majetic, S., Kollar, R., Nad, K. ve Obhodas, J., Inspecting minefields and residual explosives by fast neutron activation method, IEEE Transactions on Nuclear Science, 59, 1421-1425, (2012).

[41] Bielecki, Z., Janucki, J., Kawalec, A., Mikolajczyk, J. ve Palka, N., Sensors and systems for the detection of explosive devices - an overview, Metrology and Measurement Systems, XIX, 3-28, (2012).

[42] Macdonald, J., Lockwood, J.R., Mcfee, J., Altshuler, T. ve Broach, T., Alternatives for landmine detection, CA: RAND, Technical report, Santa Monica, ABD, (2003).

[43] Mikhaltsevitch, V. T., Techniques used for 14N NQR studies, Annual Reports on NMR Spectroscopy, 66, 149-194, (2009).

[44] Heuvel, J. ve Fiore, F., Simulation study of x-ray backscatter imaging of pressure-plate improvised explosive devices, Detection and Sensing of Mines, Explosive Objects and Obscured Targets XVII, 835716-1-835716-15, (2012).

[45] King, C., Blagden, P., Rhodes, G., Maresca, L.ve Wheatley, A., Mine action : lessons and challenges, Technical report, Geneva International Centre for Humanitarian Demining, Geneva, İsviçre, (2005). 
[46] Church, P., Mcfee, J.E., Gagnon, S. ve Wort, P., Electrical impedance tomographic imaging of buried landmines, IEEE Transactions on Geoscience and Remote Sensing, 44, 2407-2420, (2006).

[47] Chi, W., Ying-Jie, Y. ve Xing-Fei, L., An acoustic-to-seismic coupling based landmines detection system in lab-scale experimental environment, Journal of Tianjin University, 160-166, (2011).

[48] Bruschini, C. ve Gros, B., A Survey of research on sensor technology for landmine detection, Journal of Humanitarian Demining, 2, 1, (1998).

[49] Coronado-Vergara, J., Avina-Cervantes, G., Devy, M. ve Parra, C., Towards landmine detection using artificial vision, IEEE International Conferance on Intelligent Robots and Systems, 659-664, (2005).

[50] Messelink, W., Schutte, K., Vossepoel, A., Cremer, F., Schavemaker, J. ve Breejen, E., Feature-based detection of landmines in infrared images, Proceedings of SPIE, Detection and Remediation Technologies for Mines and Mine like Targets VII, 4742, 108-119, (2002).

[51] Cremer, F., Jong, W., Schutte, K., Yarovoy, A. G.ve Kovalenko, V., Feature level fusion of polarimetric infrared and gpr data for landmine detection, International Conferance on Requirements and Technologies for the Detection, Removal and Neutralization of Landmines and UXO, 638-642, (2003).

[52] Frigui, H., Gader, P. D., Keller, J. M.ve Schutte, K., Fuzzy clustering for land mine detection, Conference of the North American Fuzzy Information Processing Society - NAFIPS,261-265, (1998).

[53] Roughan, M., McMichael, D. W., Ho, K. C., Yarovoy, A. G. ve Kovalenko, V., A comparison of methods of data fusion for land-mine detection, International Workshop on Image Analysis and Information Fusion, (1997).

[54] Jarrad, G. A. ve McMichael, D. W., Improving multispectral mine detection methodsby compensating for clutter, Australian-American Joint Mine Warfare Conference, 1-4, (1999).

[55] Habib, M.K., Humanitarian demining mine detection and sensors, IEEE International Symposium on Industrial Electronics (ISIE),2237-2242, (2011).

[56] Kolba, M.P., Torrione, P.A. ve Collins, L.M., Fusion of ground-penetrating radar and electromagnetic induction sensors for landmine detection and discrimination, Detection and Sensing of Mines, Explosive Objects, and Obscured Targets XV, 76641S-1-76641S-7, (2010).

[57] Hibbs, A. D., Alternatives for Landmine Detection in Rand, Chapter Nuclear Quadrupole Resonance,169-189, Rand, Skokie, (1999).

[58] Wu, C., Digging in the dirt: chemical and biological sensors could aid the search for hidden land mines, Science News, 153, 13, 202-204, (1998).

[59] Achkar, R., Owayjan, M. ve Mrad, C., Landmine detection and classification using MLP, 2011 Third International Conference on Computational Intelligence, Modelling and Simulation, 1-6, (2011). 